\title{
Adjuvant high-dose-rate interstitial brachytherapy for malignant peripheral nerve sheath tumor of the foot: a case report
}

\author{
Andrea Vavassori, MD!' Elisabetta Pennacchioli, MD², Matteo Augugliaro, MD!, Stefano Durante, MD!, \\ Samantha Dicuonzo, MD', Gian Marco Orsolini, MD², Pierpaolo Prestianni, MD², Raffaella Cambria, MSc

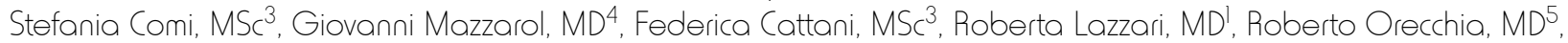 \\ Barbara Alicja Jereczek-Fossa, MD!,6 \\ 'Department of Radiotherapy, IEO European Institute of Oncology IRCCS, Milan, Italy, ${ }^{2}$ Division of Sarcoma and Melanoma, IEO European \\ Institute of Oncology IRCCS, Milan, Italy, ${ }^{3}$ Unit of Medical Physics, IEO European Institute of Oncology IRCCS, Milan, Italy, ${ }^{4}$ Department \\ of Pathology and Laboratory Medicine, IEO European Institute of Oncology IRCCS, Milan, Italy, ${ }^{5}$ Scientific Directorate, IEO European Institute \\ of Oncology IRCCS, Milan, Italy, UUniversity of Milan, Department of Oncology and Hemato-Oncology, Milan, Italy
}

\begin{abstract}
Soft tissue sarcomas of the foot are extremely rare and can therefore be misdiagnosed as benign diseases, and be prematurely removed with an unplanned excision. The standard treatment is a wide local excision with an addition of radiotherapy as an alternative to a radical resection (e.g., below-knee or foot amputation). We report on a patient with primary malignant peripheral nerve sheath tumor in the foot plantar soft tissue, who had no evidence of the disease and no severe late toxicity higher than grade 2, 40 months after receiving amputation of toes and adjuvant interstitial high-dose-rate brachytherapy (HDR-BT). To the best of our knowledge, only a few cases were treated with HDR-BT with this scenario. From our findings, HDR-BT could be a safe and quick treatment option for these types of lesions.

Key words: interstitial HDR brachytherapy, foot soft tissue sarcoma, MPNST, lower extremity.

\section{Purpose}

Malignant soft tissue sarcomas (STS) of the foot are rare, occurring at a rate of less than $5 \%$ of soft tissue malignancies $[1,2]$.

Usually, patients are asymptomatic, unless there is a mass effect or invasion of nerve sheath. Their unplanned surgical excision (USE) without appropriate diagnostic evaluation or staging is quite common (40-55\%), and inadequate procedures are reported to have adverse effects on prognosis and functional outcomes [3-7].

This is due to the rarity of STS and higher prevalence of benign lesions, delaying the referral to a sarcoma center, where therapeutic management could be planned by a dedicated multidisciplinary team $[8,9]$.

Soft tissue sarcomas arising in the hand or foot and ankle present a technical challenge. The additional surgical excision tends to be more extensive than the first resection, because of the need to obtain complete tumor removal with an appropriately wide margin of resection. Irradiation can be performed using external beam radiotherapy (EBRT), brachytherapy (BT), intra-operative ra- diotherapy (IORT), proton therapy, or a combination of them.

Post-operative irradiation is commonly used in patients who underwent prior USE or in case of high-grade sarcomas, tumors greater than or equal to $5 \mathrm{~cm}$, or positive surgical margins to enhance local control (LC), as stated by randomized trials [10-12].

Alternatively, pre-operative EBRT can increase tumor resectability in unresectable cases, and requires a lower radiation dose and smaller treatment volumes, mitigating long-term toxicity $[13,14]$.

As far as the histological diagnosis is considered, malignant peripheral nerve sheath tumors (MPNSTs) account for about $10 \%$ of all STSs [15]. They are often associated with neurofibromatosis type 1 (NF-1, von Recklinghausen disease), which represents a negative prognostic factor determining a worse disease-specific survival (DSS). They are malignant neoplasms of ectomesenchymal origin of the peripheral nerves, commonly occurring in the trunk in association with major nerves, such as the sciatic nerve, spinal roots, and brachial plexus, and af-
Address for correspondence: Matteo Augugliaro, MD, Department of Radiotherapy, European Institute of Oncology IRCCS, via Ripamonti 435, 20141, Milan, Italy, phone: +39 0257483037, e-mail: matteo.augugliaro@ieo.it
Received: 03.07 .2020

Accepted: 20.03.2021

Published: 18.05 .2021 
fecting extremity locations, in particular in their proximal portions, in about $45 \%$ of patients. Usually, they grow invading the surrounding tissue in an infiltrative pattern, with radicular pain, motor weakness, and/or associated paraesthesia [16-19].

MPNSTs rarely arise in bone, in particular mandible, spine, and long bones of extremities; the origin from small hand and foot bones is exceptionally rare [20-23]. MPNSTs are high-grade tumors, with a significant risk of local recurrence as well as systemic metastasis. The suggested treatment is limb-sparing surgery with radiotherapy as an alternative to radical below-knee amputation or foot amputation [24, 25], even if a wide resection margins and functional preservation could be difficult to achieve by the surgeon.

Different clinical trials are available for NF-1 patients with MPNST investigating the use of mitogen-activated protein kinase (MEK) inhibitors, tyrosine kinase inhibitors, mammalian target of rapamycin (mTOR) inhibitors and programmed death-1 (PD-1) inhibitors, interferons or chemotherapy [26].

\section{Case report}

In January 2015, a 42-year-old man was admitted to a hospital due to a painful, slow growing mass on his left foot, affecting his gait and creating numbness of his toes. A magnetic resonance imaging (MRI) showed a $34 \mathrm{~mm}$ well-defined lesion within subcutaneous tissue between the I and II metatarsus. He received anti-inflammatory drugs and continued to use painkillers with partial relief. One year later, in July 2016, a new MRI revealed an increase of the nodular lesion of up to $60 \times 40 \mathrm{~mm}$ (Figure 1A). In October 2016, a fragmented excision of the mass into two blocks was performed diagnosing soft tissue mesenchymal tumor with high mitotic rate, $>20$ mitoses per 10 high-power fields (HPF), Ki67 proliferative index of $45 \%$. According to imaging, surgical, and histopathological findings, the diagnosis of MPNST vs. fibrosarcoma was rendered. In November 2016, after an MRI showing a residual nodular lesion of $30 \times 20 \mathrm{~mm}$ at the II metatarsus (Figure 1B), he was referred to our musculoskeletal oncology service. Second opinion confirmed the pathological diagnosis of MPNST, with immuno-histology for P75, S-100 protein, SOX-10, smooth-muscle actin and desmin, CD34, and FISH test for 18q11 (SS18) consistent with the original diagnosis. A multidisciplinary tumor board proposed to evaluate the feasibility of a radical surgery with adjuvant BT as an alternative to foot amputation. The diagnostic work up with total body computerized tomography (CT) was negative for distant disease. Before administering the treatment, a written informed consent of the patient was obtained for the use of his anonymized data for research and educational purposes. In January 2017, he received a wide local excision "en bloc" of the tumor, including the II and III metatarsus and corresponding toes (Figure 2). Intra-operatively, 12 plastic afterloading catheters (Nucletron, Elekta, Sweden) were placed in the tumor bed and surrounding healthy tissues, and secured with plastic buttons without skin sutures. The catheters were implanted in a crossshaped configuration, with a plane parallel to the sole and an orthogonal plane between the I and IV metatarsus, and held in place using Jackson-Pratt technique (Figure 3) $[27,28]$. The wound was closed with absorbable vicryl suture for subcutaneous tissue and non-absorbable suture of the skin. On gross examination, in the excised specimen, a $28 \mathrm{~mm}$ in major size residual neoplasia of the soft tissue was detected, and at least $1 \mathrm{~cm}$ margin resected beyond the gross disease.

The final diagnosis of MPNST, G2 was made, with 17 mitoses per $10 \mathrm{HPF}$, infiltrating the skeletal muscle and extended near the periosteum, with an associated area of necrosis (Figure 4). Resection margins, both in bone and in soft tissue, showed no evidence of neoplasia. A CT simulation scan with $2.5 \mathrm{~mm}$ slice thickness and separation was
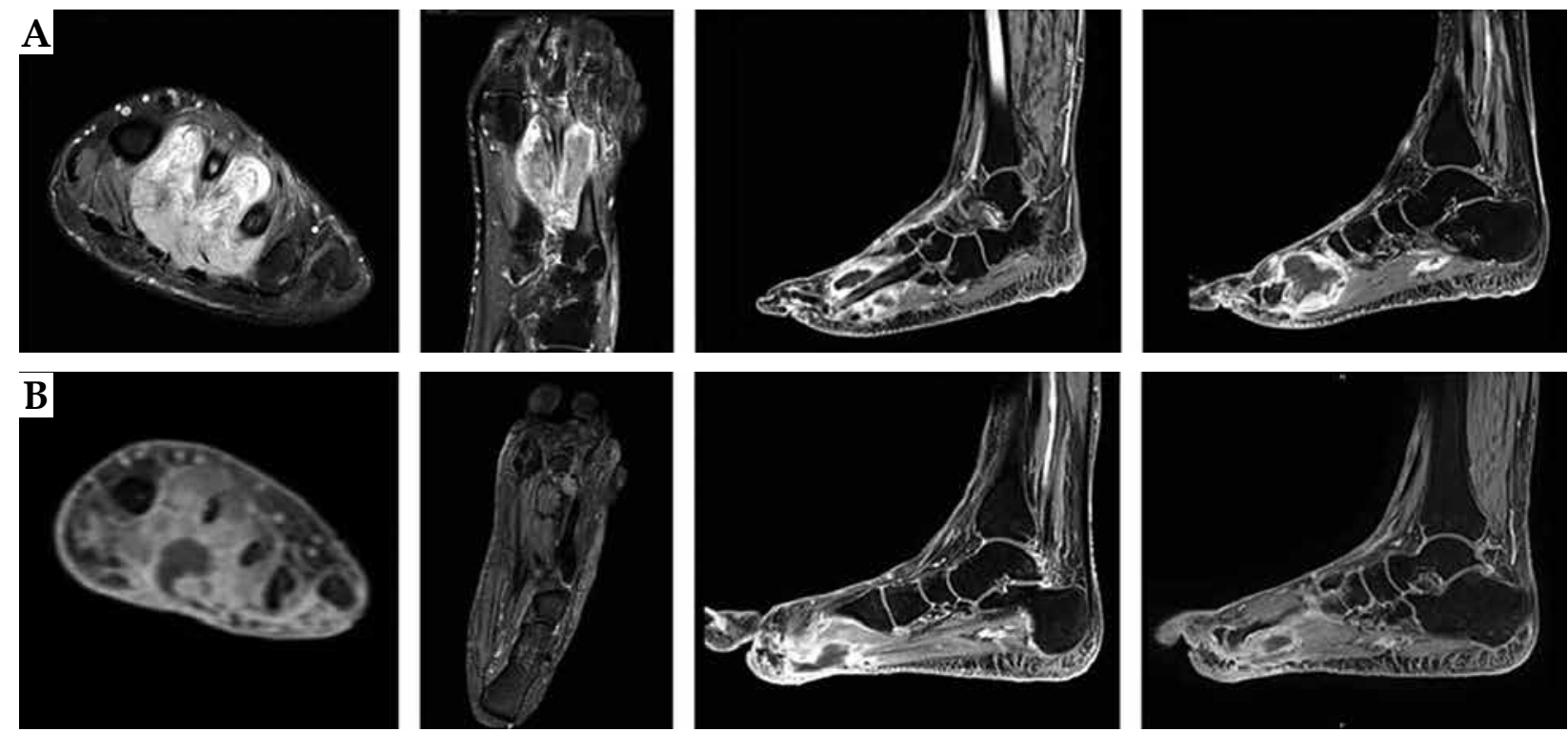

Fig. 1. Magnetic resonance images of the left foot showing the heterogeneous lesion before (A) and after (B) the first fragmented surgical excision 

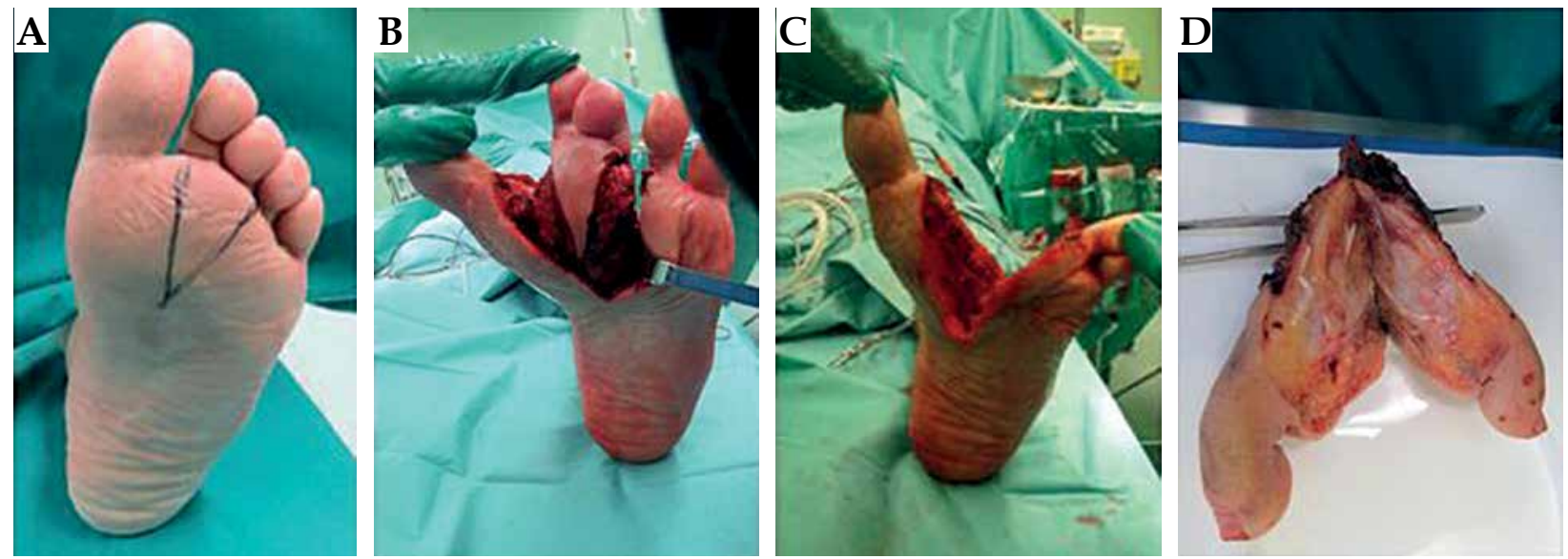

Fig. 2. Wide local excision (A-C) including the II and the III metatarsus and the corresponding toes with the demolition "en bloc" of the tumor (D)
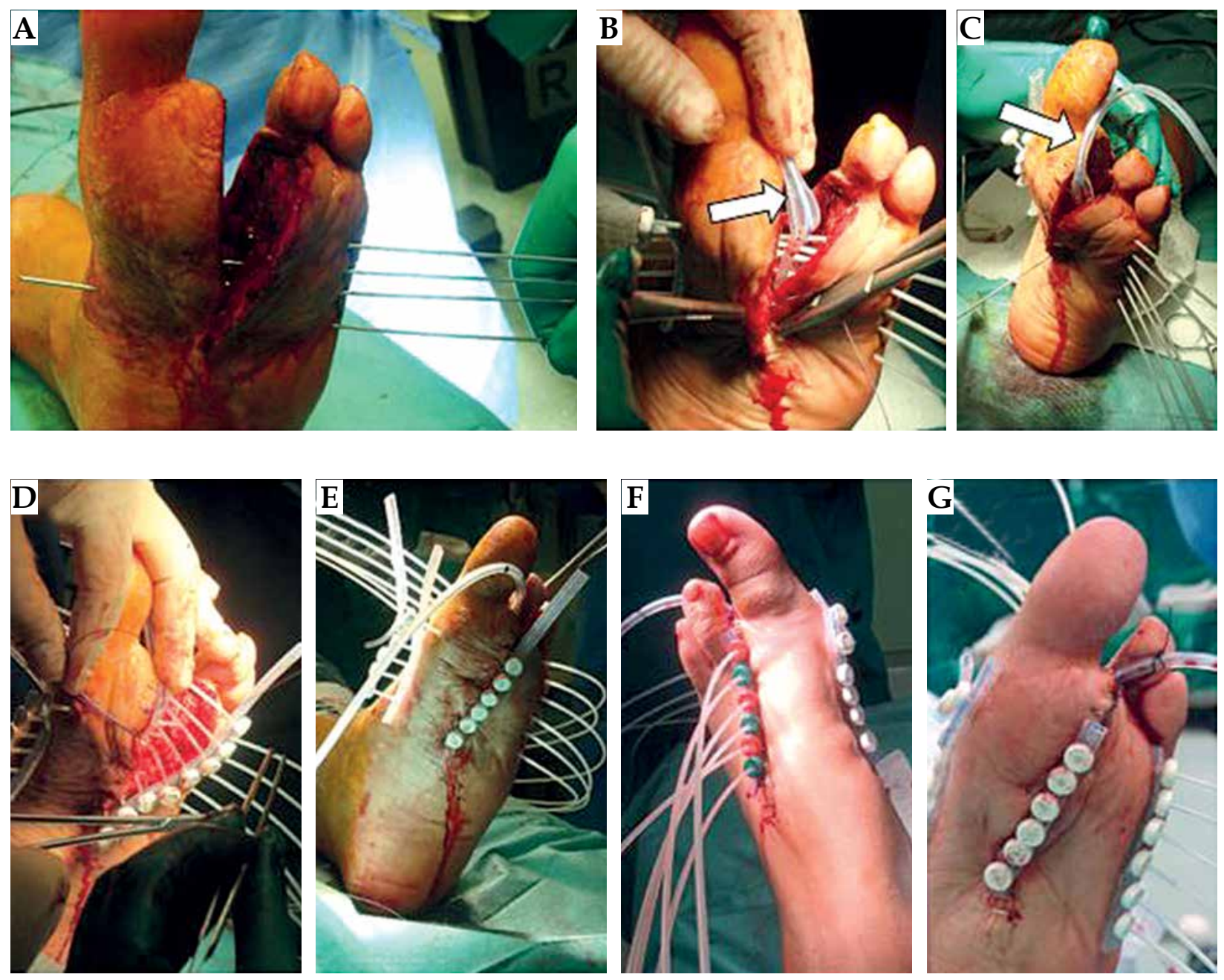

Fig. 3. Brachytherapy implant procedure. Stainless steel guide needles (A) and afterloading catheters (B, C). The final crossshaped configuration with a plane parallel to the sole and an orthogonal plane between the I and the IV metatarsus (D). Catheters were held in place using Jackson-Pratt drain (white arrow) and secured by plastic buttons (E-G) 

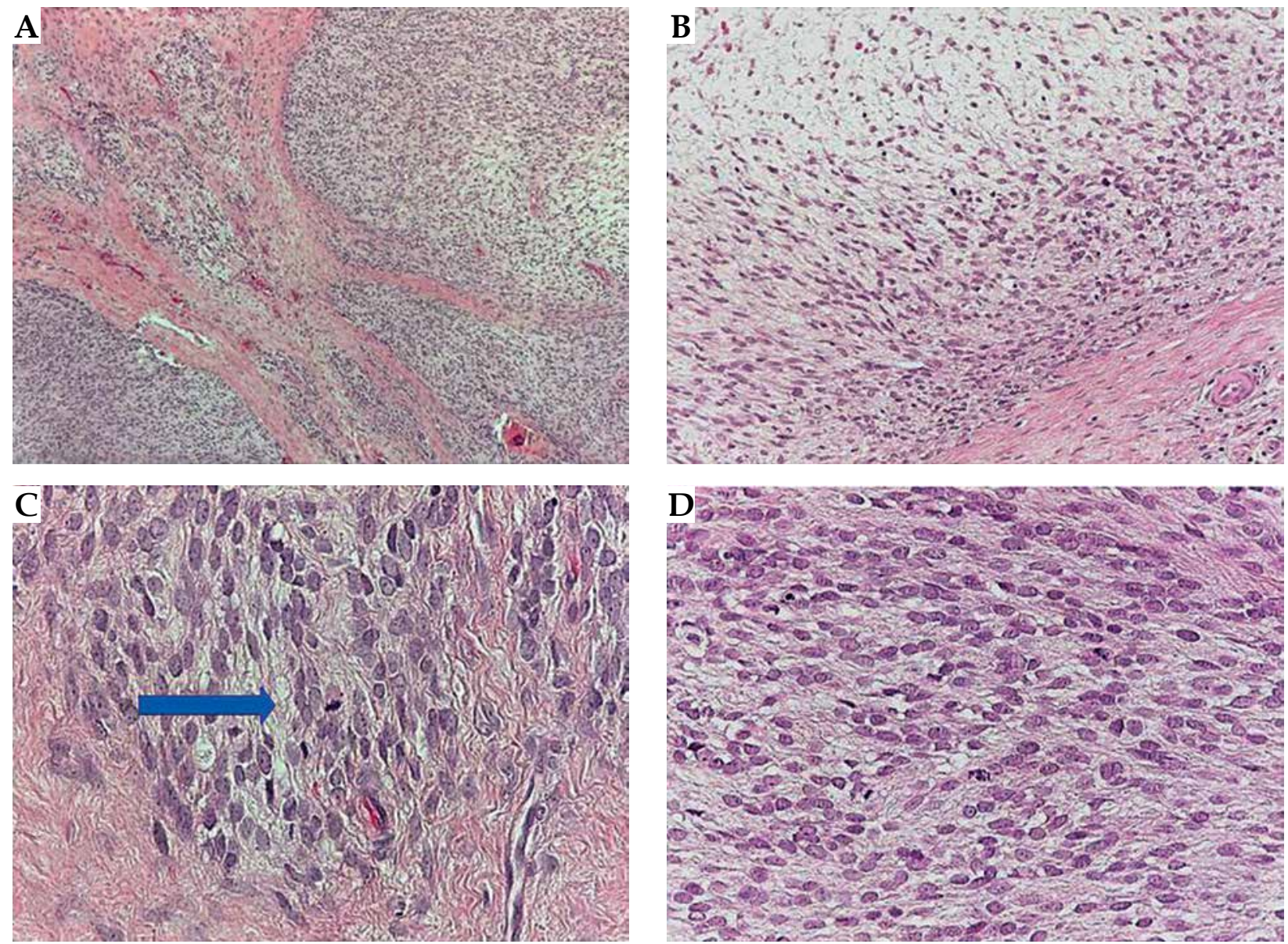

Fig. 4. Histopathologic evaluation. Low power field $(4 \times)$ depicted a spindle cells neoplasm with infiltrative borders (A); with looser mixoid-like areas (B), with some atypical mitoses (C, blue arrow), and huge number of mitotic figures (D)

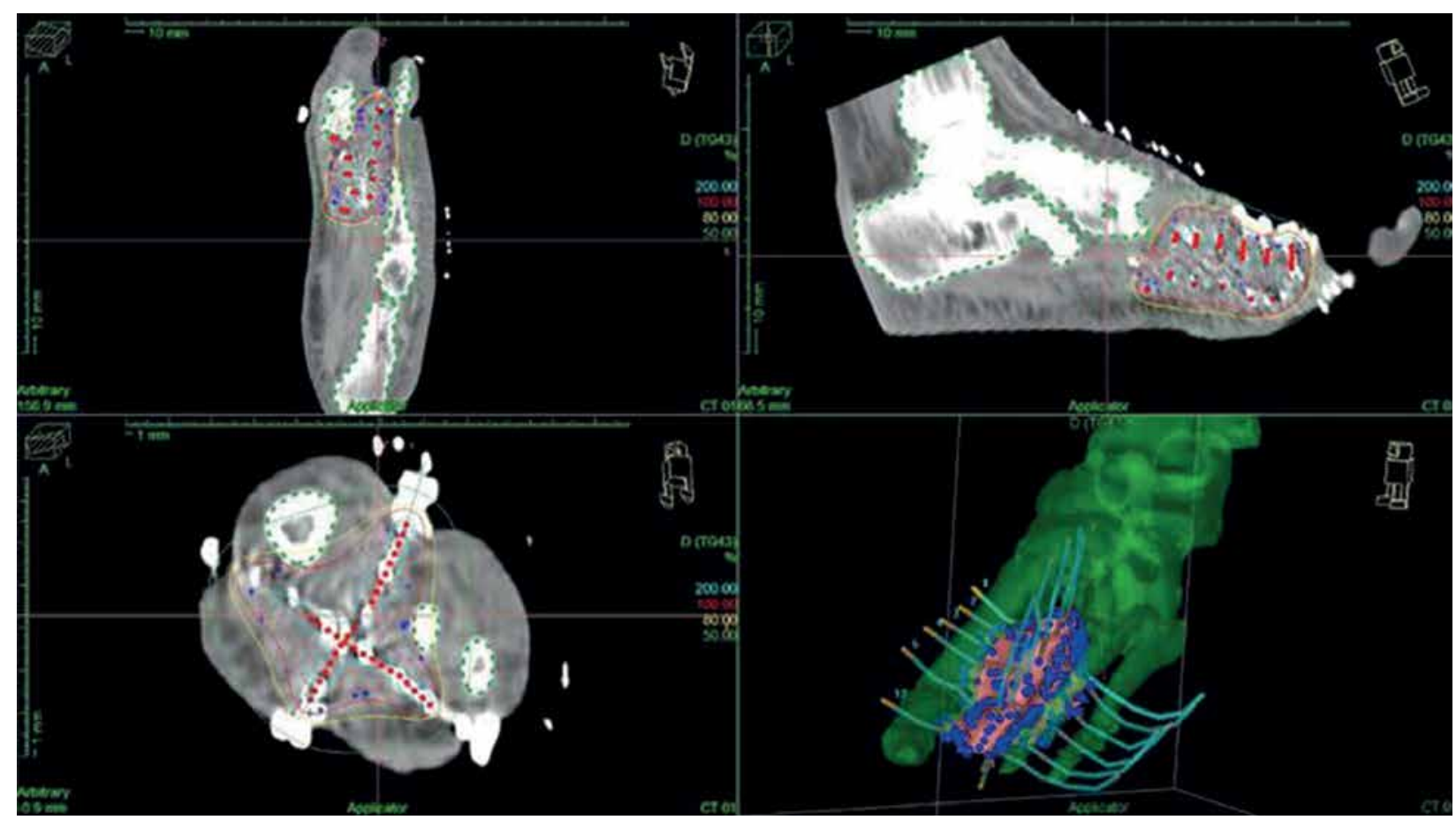

Fig. 5. Treatment plan 
Table 1. Dose volume histogram (DVH) parameters obtained, and dose constraints used for clinical target volume (CTV) and organs at risk

\begin{tabular}{|c|c|c|c|}
\hline Volume & Constraints & Present case & ABS common/ideal values \\
\hline \multirow[t]{3}{*}{ CTV } & $\mathrm{D}_{90}$ & $117.4 \%$ (4.11 Gy) & $\geq 90 \% / \geq 100 \%$ \\
\hline & $V_{100}$ & $97.1 \%$ & $\geq 90 \% / \geq 95 \%$ \\
\hline & $V_{150}$ & $60.1 \%$ & $\leq 50 \% / \leq 40 \%$ \\
\hline \multirow[t]{2}{*}{ TV } & $V_{100}$ & $86.5 \%$ & - \\
\hline & $V_{150}$ & $3.2 \%$ & - \\
\hline \multirow[t]{3}{*}{ Bones } & $\mathrm{D}_{0.1 \mathrm{lcc}}$ & $142.7 \%$ (total dose 49.9 Gy) & Total dose < 43 Gy \\
\hline & $D_{1 c c}$ & 101\% (total dose 35.4 Gy) & Total dose < 35 Gy \\
\hline & $D_{2 c c}$ & 92.3\% (total dose 32.3 Gy) & - \\
\hline \multirow[t]{3}{*}{ Skin } & $D_{0.1 c c}$ & 150.5\% (total dose 52.6 Gy) & Total dose < 40 Gy \\
\hline & $\mathrm{D}_{1 \mathrm{cc}}$ & 77.1\% (total dose 26.9 Gy) & - \\
\hline & $D_{2 c c}$ & 62.2\% (total dose 21.7 Gy) & Total dose < 37 Gy \\
\hline
\end{tabular}

ABS - American Brachytherapy Society, CTV - clinical target volume, TV - tissue volume, $D_{0.1 c c}$ - dose to $0.1 \mathrm{cc}$ of the organ, $D_{1 c c}-$ dose to $1 c c$ of the organ, $D_{2 c c}-$ dose to 2 cc of the organ, $D_{90}$-dose to the $90 \%$ of the volume, $V_{100}$-volume encompassed by the $100 \%$ isodose, $V_{150}$-volume encompassed by the $150 \%$ isodose

performed and entered into BT treatment planning system (Oncentra Brachy, Nucletron, Elekta, Stockholm, Sweden), allowing for reconstruction of catheters, definition of clinical target volume (CTV = tumor bed between the I and IV metatarsus and sole with a safety margin of about $10 \mathrm{~mm}$ ), and nearby organs at risk (OARs), i.e., bones and skin. Computerized optimization of dwell positions and times of the stepping source was performed for fine-tuning of the isodose distributions (Figure 5 and Table 1). According to the American Brachytherapy Society (ABS) recommendations, the evaluated target parameters included the percentage of the CTV receiving $100 \%\left(\mathrm{~V}_{100}\right)$ and $150 \%\left(\mathrm{~V}_{150}\right)$ of the prescribed dose, and the dose to $90 \%$ of the CTV $\left(D_{90}\right)$. Tissues constraints for uninvolved OARs (skin and bones) were based on highest dose to $0.1 \mathrm{cc}\left(\mathrm{D}_{0.1 \mathrm{cc}}\right), 1 \mathrm{cc}\left(\mathrm{D}_{1 \mathrm{cc}}\right)$, and/or $2 \mathrm{cc}\left(\mathrm{D}_{2 \mathrm{cc}}\right)$. Dose homogeneity index (DHI) was defined as:

$$
\mathrm{DHI}=\left(\mathrm{TV}_{100}-\mathrm{TV}_{150}\right) / \mathrm{TV}_{100}
$$

where $\mathrm{TV}_{100}$ and $\mathrm{TV}_{150}$ are the whole tissue volume encompassed by $100 \%$ and $150 \%$ of the prescribed dose, respectively, equal to 0.61 , as recommended as a minimum [25].

Outpatient fractionated BT was started nine day after the surgery, using MicroSelectron digital HDR afterloader (Nucletron, Elekta, Sweden) containing a single Iridum-192 source. Before the administration of each treatment fraction, the implant was examined by the radiation therapist and radiation oncologist to ensure there was no critical displacement of the catheters.

A total dose of 35 Gy in 10 fractions, 2 fractions per day, with a minimum interval of $6 \mathrm{~h}$ in-between, was administrated in 5 consecutive days, emulating the treatment schedule proposed by the NCCN guidelines (36 Gy in 10 fractions of 3.6 Gy over 5 days) [29], with a lower dose applied due to the challenging site.

At the end of the last fraction, the implant catheters were removed. No technical problems, such as collapses or kinking of flexible catheters, allowing temporary or definitive breakdowns of treatment were recorded.

The procedure was well-tolerated without severe pain or discomfort during the treatment. Acute and late side effects were classified according to the Radiation Therapy Oncology Group (RTOG) and the European Organization for Research and Treatment of Cancer (EORTC) scale [30]. During the follow-up time, every 6 months for the first year and then annually, a routine MRI, total body $\mathrm{CT}$, and clinical examination were performed to assess local and distant control. One year after the irradiation, the patient experienced a superficial wound infection that was treated with topic antibiotics. No severe acute and late toxicity higher than grade 2 was reported (no pain, no suture dehiscence, no fibrosis, no fractures). At the last follow-up, 40 months after surgery and HDR-BT treatment, the patient had no evidence of clinical recurrence (Figures 6 and 7).

\section{Discussion}

Due to the relative rare incidence of MPNST, the significant role of irradiation is still being defined, and only very few patients have been treated with brachytherapy (Table 2). Wong et al. reported on 134 consecutive patients affected by MPNST, and 36 of them presented with extremity sites localization. Eighteen and 61 patients received pre-operative and adjuvant EBRT, respectively. Sixteen patients received IORT, 12 patients received BT as a boost, and 2 patients were treated with BT only. After a median follow-up of 53 months, $42 \%$ of patients were disease-free, with a LC at 5 years of $49 \%$. On univariate and multivariate analysis, the use of interventional radiotherapy (IORT or BT) was a significant prognostic factor for overall survival (OS) and LC [16]. A study by Kahn et al. showed clinical results of adjuvant irradiation in both sporadic (15) and NF-1-associated (18) MPNST patients, 8 and 11 of them with a lesion located at the extremities, respectively. Among them, twenty patients were treated with EBRT and only 4 patients received BT. Although irradiation can be effective in achieving LC, it was not found to be a prognostic factor for OS [31].

A comparable result was obtained with EBRT by Anghileri et al. in a cohort of 205 patients with primary (130 patients) or recurrent (75 patients) MPNST. In their 

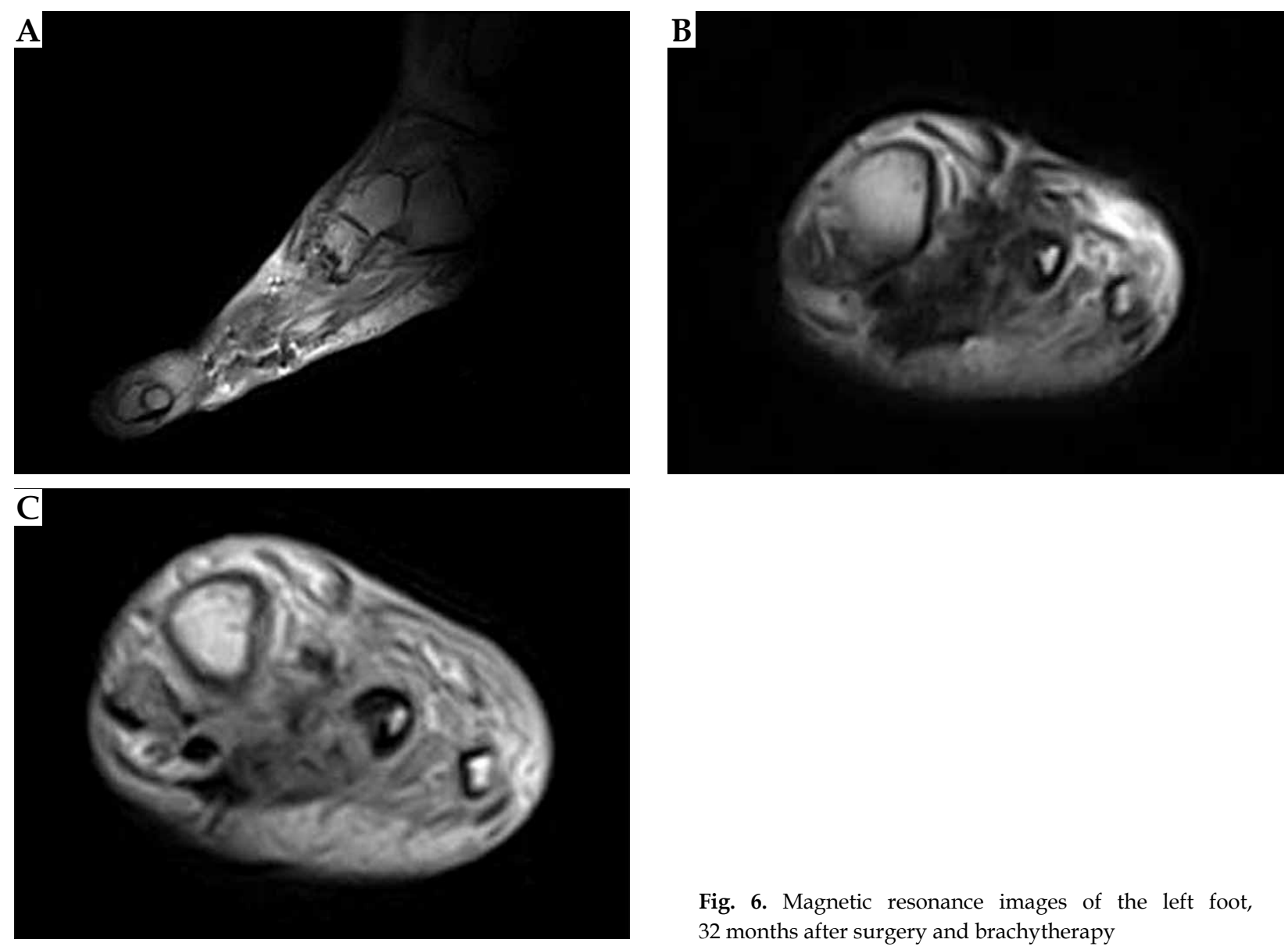

Fig. 6. Magnetic resonance images of the left foot, 32 months after surgery and brachytherapy
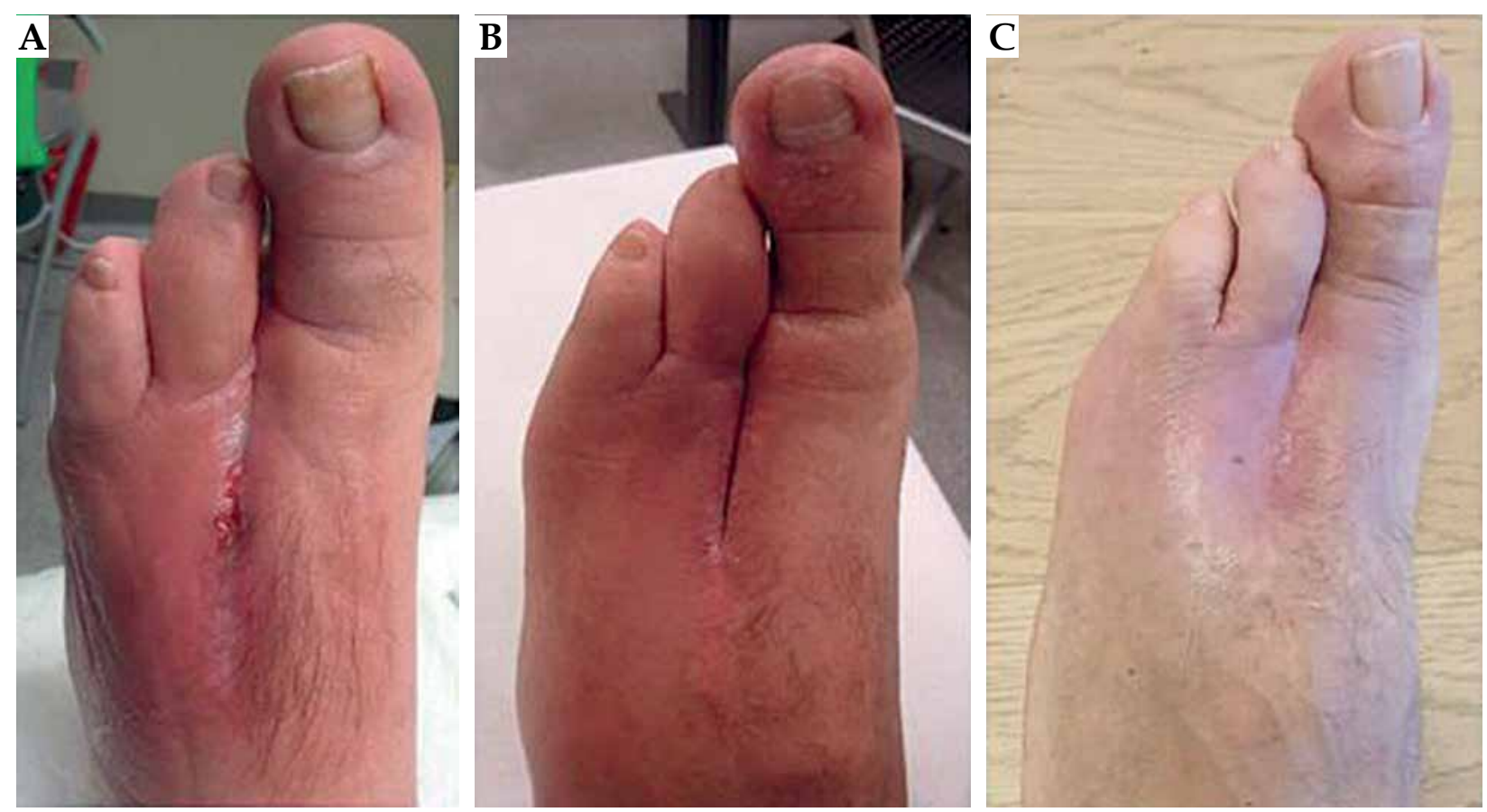

Fig. 7. Follow-up at 4 months (A), 10 months (B), and 40 months (C) after the treatment 
Table 2. Overview of relevant publications

\begin{tabular}{|c|c|c|c|c|}
\hline Author, year [ref.] & Number of patients & $\begin{array}{l}\text { Treatment modality } \\
\text { (median dose or range) }\end{array}$ & $\begin{array}{l}\text { Follow-up } \\
\text { (median) }\end{array}$ & $\begin{array}{l}\text { Clinical results } \\
\text { (all pts) }\end{array}$ \\
\hline $\begin{array}{l}\text { Wong et al., } \\
1998 \text { [16] }\end{array}$ & 134 (36 ESL) & $\begin{array}{c}18 \text { pts neoadj-RT (50.4 Gy) } \\
61 \text { pts adj-RT (50.7 Gy) } \\
16 \text { pts IORT (12.5 Gy) } \\
12 \text { pts BT as a boost (15 Gy) } \\
2 \text { pts BT only (40-45 Gy) }\end{array}$ & 53 months & $\begin{array}{l}5 \text {-year LC-49\% } \\
5 \text {-year OS - 52\% }\end{array}$ \\
\hline $\begin{array}{l}\text { Anghileri et al., } \\
2006[32]\end{array}$ & $\begin{array}{l}205 \text { (92 ESL) } \\
130 \text { primary } \\
75 \text { recurrent } \\
\end{array}$ & 91 pts (57 Gy) & 112 months & $\begin{array}{c}10 \text {-year LC }-71.2 \% \\
10 \text {-year DSS - } 56.7 \%\end{array}$ \\
\hline $\begin{array}{l}\text { Kar et al., } \\
2006 \text { [33] }\end{array}$ & 24 (15 ESL) & 16 adj-RT (58 Gy) & 38 months & $\begin{array}{l}5 \text {-year OS - 58\% } \\
5 \text {-year DFS - 38\% }\end{array}$ \\
\hline $\begin{array}{l}\text { Stucky et al., } \\
2012 \text { [15] }\end{array}$ & 175 (78 ESL) & $\begin{array}{c}110 \text { pts adj-RT } \\
\text { (37 IORT) } \\
49 \text { neoadj CT or RT }\end{array}$ & 74 months & $\begin{array}{c}\mathrm{LC}-88 \% \\
5 \text {-year DSS - 60\% } \\
10 \text {-year DSS - 45\% }\end{array}$ \\
\hline $\begin{array}{l}\text { Kahn et al., } \\
2014 \text { [31] }\end{array}$ & $\begin{array}{c}33 \\
15 \text { sporadic (8 ESL) } \\
18 \text { NF-1-associated } \\
\text { (11 ESL) }\end{array}$ & $\begin{array}{c}15 \text { adj-RT (58.5-59.4 Gy) } \\
2 \text { BT as a boost } \\
2 \text { BT only } \\
1 \text { proton therapy }\end{array}$ & - & 5 -year OS - $43.7 \%$ \\
\hline $\begin{array}{l}\text { Bishop et al., } \\
2018 \text { [34] }\end{array}$ & 71 (46 ESL) & $\begin{array}{l}23 \text { pts neoadj-RT (50 Gy) } \\
48 \text { pts adj-RT (64 Gy) }\end{array}$ & 118 months & $\begin{array}{c}10 \text {-year LC - 78\% } \\
10 \text {-year DFS - 48\% } \\
10 \text {-year OS - 54\% }\end{array}$ \\
\hline
\end{tabular}

Adj-adjuvant, BT - brachytherapy, CT - chemotherapy, ESL - extremity sites localization, DFS - disease-free survival, DSS - disease-specific survival, IORT - intraoperative radiotherapy, LC - local control, neoadj-neoadjuvant, OS - overall survival, RT - radiotherapy, pts - patients

study, lack of EBRT was a negative prognostic factor for DSS [32]. Similarly, Kar and colleagues presented a retrospective analysis of 24 MPNST patients, with 15 of them with extremity lesions. Post-operative EBRT group showed no statistically significant growth of DFS and OS [33].

On the contrary, the updated results of Wong's series published by Stucky in 2012 (175 patients, 78 with extremity site's location) showed no significant predictors for local recurrence on univariate analysis [15].

More recently, Bishop et al. analyzed data of 71 consecutive patients treated with surgery and EBRT for localized MPNST, and reported that in univariate analysis, only margin status was significantly associated with LC [34].

It should be emphasized that the distinctive anatomy of the foot presents challenges for complete surgical resection and reconstruction [35], and the application of a standard approach of limb-sparing surgery and irradiation could not be feasible in all patients, particularly in case of previous unplanned excision that often results in the need for more aggressive surgery, which may impact oncological outcomes $[5,36]$.

Saeed et al. evaluated a dataset of 245 patients affected by STS of the extremity and chest-wall treated with planned (211) or unplanned (34) excision. In case of USE, the use of pre-operative EBRT (11 patients) followed by re-excision improved LC and progression-free survival (PFS) compared to adjuvant irradiation (6 patients) [14].

A study by Latt and colleagues reviewed 16 patients with STS of the foot treated over a 15-year period. Eight patients were referred after USE, and $50 \%$ of them had a documented progression of local disease at the time of presentation. Radiation therapy was used pre-operatively in 5 patients (4 primary STS and 1 USE) and post-oper- atively in 7 patients ( 2 primary STS and 5 USE). No data about dose and technique of irradiation were reported. Local recurrence and distant metastases occurred in 2 and 4 patients, respectively. There were four post-operative complications, but irradiation was not related with any long-term morbidity [37].

Several reports in literature indicated that lower extremities STS have higher rates of wound complications, bone fracture, and joint contracture, which could affect patients' quality of life [38]. Houdek et al. published a study on 62 patients with STS of the foot and ankle, with 16 and 15 patients receiving neoadjuvant and adjuvant irradiation (BT was used in 4 patients), respectively. The authors found that patients with pre-operative EBRT were at increased risk of complications (e.g., wound dehiscence, infection, or skin graft failure) [39].

Wound complications are not limited to patients treated with radiotherapy, since they could also be seen after sole surgery treatments. Up to date, only few reports analyzed the tolerance of skin grafts or flaps in post-operative RT or BT [40]. In small tumors, primary suture or a rotation flap are generally used, while in bigger lesions, a free flap or vacuum (VAC) therapy can be indicated in order to increase local blood flow, decrease bacterial growth, and promote granulation tissue.

In the BrachyVac technique, the required number of afterloading catheters and drainage tube were inserted into the polyurethane sponge of the vacuum system. The sponge was cut to size appropriate for filling the cavity of the tumor resection, and patients received HDR-BT to a total dose of 15-18 Gy in 5-6 fractions. The system was removed in a second surgical intervention shortly after the last fraction [41]. 
The use of BT in STS has a history of several decades, even if its indication in lesions of the foot seems subjective, because of the increased risk of complications due to the low distance between the skin and bones, especially in case of phalangeal tumors [1]. In fact, the ABS does not recommend the use of BT in the primary management of acral lesions near finger joints [25].

Even though in the present study, the nominal total doses to OARs were higher than the recommended ones, no severe acute and late toxicities higher than grade 2 were observed. This was probably because of the peculiar technical solutions adopted for implant geometry. As a matter of fact, the cross-shaped configuration was used to increase the dose in the thin space between the I and the IV metatarsus, with valuable Jackson-Pratt drain technique to avoid catheters' displacement. Moreover, the post-treatment rehabilitation and wound care were useful to minimize adverse effects of the surgery and adjuvant irradiation.

To the best of our knowledge, only a few cases have been treated with adjuvant HDR-BT without EBRT in this scenario. Actually, there are many signs of a renewed interest in BT, and specific strategic interventions must be carried out in the field of national guidelines, education, research, and communication with patients and colleagues of other specialties [42].

\section{Conclusions}

Despite the several limitations of a single case report and the infrequent presentation site of the disease, our data supports the concept that HDR-BT is a feasible and effective treatment for STS of the foot.

We encourage a multidisciplinary approach in the management of these rare tumors to optimize oncological and functional outcomes.

\section{Acknowledgements}

This work was partially supported by the Italian Ministry of Health with Ricerca Corrente and $5 \times 1000$ funds.

\section{Disclosure}

The authors report no conflict of interest.

\section{References}

1. Mascard E, Gaspar N, Brugières L et al. Malignant tumours of the foot and ankle. EFORT Open Rev 2017; 2: 261-271.

2. Jyothirmayi R, Sittampalam Y, Harmer C. Soft tissue sarcoma of the hand or foot: conservative surgery and radiotherapy. Sarcoma 1999; 3: 17-24.

3. Nishimura A, Matsumine A, Asanuma $\mathrm{K}$ et al. The adverse effect of an unplanned surgical excision of foot soft tissue sarcoma. World J Surg Oncol 2011; 9: 160.

4. Arai E, Nishida Y, Tsukushi $S$ et al. Clinical and treatment outcomes of planned and unplanned excisions of soft tissue sarcomas. Clin Orthop Relat Res 2010; 468: 3028-3034.

5. Thacker MM, Potter BK, Pitcher JD et al. Soft tissue sarcomas of the foot and ankle: impact of unplanned excision, limb salvage, and multimodality therapy. Foot Ankle Int 2008; 29: 690-698.
6. Bianchi G, Sambri A, Cammelli S et al. Impact of residual disease after "unplanned excision" of primary localized adult soft tissue sarcoma of the extremities: evaluation of 452 cases at a single Institution. Musculoskelet Surg 2017; 101: 243-248.

7. Pretell-Mazzini J, Barton MD Jr, Conway SA et al. Unplanned excision of soft-tissue sarcomas: current concepts for management and prognosis. J Bone Joint Surg Am 2015; 97: 597-603.

8. Gómez J, Tsagozis P. Multidisciplinary treatment of soft tissue sarcomas: An update. World J Clin Oncol 2020; 11: 180-189.

9. Tagliaferri L, Vavassori A, Lancellotta V et al. INTERACTS (INTErventional Radiotherapy ACtive Teaching School) consensus conference on sarcoma interventional radiotherapy brachytherapy) endorsed by AIRO (Italian Association of Radiotherapy and Clinical Oncology). J Contemp Brachytherapy 2020; 12: 397-404. doi:10.5114/jcb.2020.98120.

10. Yang JC, Chang AE, Baker AR et al. Randomized prospective study of the benefit of adjuvant radiation therapy in the treatment of soft tissue sarcomas of the extremity. J Clin Oncol 1998; 16: 197-203.

11. Harrison LB, Franzese F, Gaynor JJ et al. Long-term results of a prospective randomized trial of adjuvant brachytherapy in the management of completely resected soft tissue sarcomas of the extremity and superficial trunk. Int J Radiat Oncol Biol Phys 1993; 27: 259-265.

12. Pisters PW, Harrison LB, Leung DH et al. Long-term results of a prospective randomized trial of adjuvant brachytherapy in soft tissue sarcoma. J Clin Oncol 1996; 14: 859-868.

13. Haas RL. Preoperative radiotherapy in soft tissue sarcoma: from general guidelines to personalized medicine. Chin Clin Oncol 2018; 7: 41.

14. Saeed H, King DM, Johnstone CA et al. Preoperative radiation therapy followed by reexcision may improve local control and progression-free survival in unplanned excisions of soft tissue sarcomas of the extremity and chest-wall. Int J Surg Oncol 2016; 2016: 5963167.

15. Stucky CC, Johnson KN, Gray RJ et al. Malignant peripheral nerve sheath tumors (MPNST): the Mayo Clinic experience. Ann Surg Oncol 2012; 19: 878-885.

16. Wong WW, Hirose T, Scheithauer BW et al. Malignant peripheral nerve sheath tumor: analysis of treatment outcome. Int J Radiat Oncol Biol Phys 1998; 42: 351-360.

17. Valeyrie-Allanore L, Ismaïli N, Bastuji-Garin S et al. Symptoms associated with malignancy of peripheral nerve sheath tumours: a retrospective study of 69 patients with neurofibromatosis 1. Br J Dermatol 2005; 153: 79-82.

18. Smolle MA, Andreou D, Tunn PU et al. Diagnosis and treatment of soft-tissue sarcomas of the extremities and trunk. EFORT Open Rev 2017; 2: 421-431.

19. Valentin T, Le Cesne A, Ray-Coquard I et al. Management and prognosis of malignant peripheral nerve sheath tumors: The experience of the French Sarcoma Group (GSF-GETO). Eur J Cancer 2016; 56: 77-84.

20. Trevino M, Moorthy C, Kafchinski L et al. Foot plantar soft tissue malignant myoepithelioma tumor: Case report and review of the literature. Clin Imaging 2020; 61: 90-94.

21. Muthusamy S, Conway SA, Pitcher JD et al. Primary intraosseous malignant peripheral nerve sheath tumor of the medial cuneiform: a case report and review of the literature. J Foot Ankle Surg 2017; 56: 129-134.

22. Iwama $Y$, Kunisada M, Goto $H$ et al. Malignant peripheral nerve sheath tumor of the distal phalanx of the fifth toe: a case report. Acta Radiol Short Rep 2014; 3: 2047981613516033.

23. Devnani B, Biswas A, Bakhshi S et al. Primary intraosseous malignant peripheral nerve sheath tumor of metacarpal bones of the hand in a patient without neurofibromatosis 1: report of a rare case. Indian J Med Paediatr Oncol 2017; 38: 232-235. 
24. Holloway CL, Delaney TF, Alektiar KM et al. American Brachytherapy Society (ABS) consensus statement for sarcoma brachytherapy. Brachytherapy 2013; 12: 179-190.

25. Naghavi AO, Fernandez DC, Mesko N et al. American Brachytherapy Society consensus statement for soft tissue sarcoma brachytherapy. Brachytherapy 2017; 16: 466-489.

26. Marjanska A, Galazka P, Wysocki M et al. New frontiers in therapy of peripheral nerve sheath tumors in patients with neurofibromatosis type 1 : latest evidence and clinical implications. Anticancer Res 2020; 40: 1817-1831.

27. Demanes DJ, Friedman JM, Park SJ et al. Brachytherapy catheter spacing and stabilization technique. Brachytherapy 2012; 11: 392-397.

28. Kishan AU, Lee EW, McWilliams J et al. Image-guided highdose-rate brachytherapy: preliminary outcomes and toxicity of a joint interventional radiology and radiation oncology technique for achieving local control in challenging cases. J Contemp Brachytherapy 2015; 7: 327-335.

29. von Mehren M, Randall RL, Benjamin RS et al. Soft tissue sarcoma, version 2.2016, NCCN Clinical Practice Guidelines in Oncology. J Natl Compr Canc Netw 2016; 14: 758-786.

30. Cox JD, Stetz J, Pajak TF. Toxicity criteria of the Radiation Therapy Oncology Group (RTOG) and the European Organization for Research and Treatment of Cancer (EORTC). Int J Radiat Oncol Biol Phys 1995; 31: 1341-1346.

31. Kahn J, Gillespie A, Tsokos M et al. Radiation therapy in management of sporadic and neurofibromatosis type 1-associated malignant peripheral nerve sheath tumors. Front Oncol 2014; 4: 324.

32. Anghileri M, Miceli R, Fiore M et al. A. Malignant peripheral nerve sheath tumors: prognostic factors and survival in a series of patients treated at a single institution. Cancer 2006; 107: 1065-1074.

33. Kar M, Deo SV, Shukla NK et al. Malignant peripheral nerve sheath tumors (MPNST) - clinicopathological study and treatment outcome of twenty-four cases. World J Surg Oncol 2006; 4: 55.

34. Bishop AJ, Zagars GK, Torres KE et al. Malignant peripheral nerve sheath tumors: a single institution's experience using combined surgery and radiation therapy. Am J Clin Oncol 2018; 41: 465-470.

35. Ring A, Kirchhoff P, Goertz O et al. Reconstruction of soft-tissue defects at the foot and ankle after oncological resection. Front Surg 2016; 3: 15.

36. Kim YJ, Song SY, Choi W et al. Postoperative radiotherapy after limb-sparing surgery for soft-tissue sarcomas of the distal extremities. Anticancer Res 2016; 36: 4825-4831.

37. Latt LD, Turcotte RE, Isler MH et al. Case series. Soft-tissue sarcoma of the foot. Can J Surg 2010; 53: 424-431.

38. Callaghan CM, Hasibuzzaman MM, Rodman SN et al. Neoadjuvant radiotherapy-related wound morbidity in soft tissue sarcoma: perspectives for radioprotective agents. Cancers (Basel) 2020; 12: 2258.

39. Houdek MT, Beahrs TR, Wyles CC et al. What factors are predictive of outcome in the treatment of soft tissue sarcomas of the foot and ankle? Foot Ankle Spec 2017; 10: 12-19.

40. Spierer MM, Alektiar KM, Zelefsky MJ et al. Tolerance of tissue transfers to adjuvant radiation therapy in primary soft tissue sarcoma of the extremity. Int J Radiat Oncol Biol Phys 2003; 56: 1112-1116.

41. Rudert M, Winkler C, Holzapfel BM et al. A new modification of combining vacuum therapy and brachytherapy in large subfascial soft-tissue sarcomas of the extremities. Strahlenther Onkol 2010; 186: 224-228.

42. Tagliaferri L, Vavassori A, Lancellotta V et al. Can brachytherapy be properly considered in the clinical practice? Trilogy project: The vision of the AIRO (Italian Association of Radio- therapy and Clinical Oncology) Interventional Radiotherapy study group. J Contemp Brachytherapy 2020; 12: 84-89. 